\title{
CROSSLINGUISTIC RESEARCH IN APHASIA: AN OVERVIEW
}

\author{
Elizabeth Bates \\ University of California at San Diego \\ Beverly Wulfeck \\ University of California at San Diego \\ and \\ Language Research Center, Children's Hospital Research Center \\ Brian MacWhinney \\ Carnegie-Mellon University
}

(Brain and Language, 41, 123-148, 1991)

Most of us would like to believe that the different patterns of language breakdown observed in aphasic patients reflect the way that the human mind and brain are organized for language. However, because so much modern research on aphasia has been carried out in English, it is difficult to separate universal mechanisms from language-specific content. Crosslinguistic com-parisons permit us to disentangle these confounds, while we address one of the most important issues in cognitive neurobiology, the issue of behavioral and neural plasticity: How many different forms can the language processor take under a range of normal and abnormal conditions? We must have an answer to this question if we want to understand what the neural mechanisms responsible for language really are and really do.

The nine papers presented within this special crosslinguistic issue of Brain and Language provide important new information about universal and language-specific patterns of sparing and impairment, in nonfluent "agrammatic" Broca's aphasics and in fluent patients with a diagnosis of Wernicke's aphasia. These crosslinguistic studies fall into two categories: (1) research in which language type is treated as an independent variable, by conducting the same experiment with equivalent materials in two or more different languages, and (2) research in which language type is treated as a natural experiment, using the peculiar characteristics of a single language to answer a question that would be difficult to ask in (for example) English. Studies applying one or both of these cross-linguistic methods have yielded six basic findings, summarized briefly as follows.

(1) Crosslinguistic variation: First, the papers in this issue (and related crosslinguistic studies by these investigators and other research groups - see Menn and Obler, 1990) clearly demonstrate that the "same" aphasic syndromes look very different from one language to another. Indeed, language differences account for more variance than patient group differences in many of our crosslinguistic experiments to date (e.g., Bates, Friederici \& Wulfeck, 1987a \& b; 1988; Bates, Friederici, Wulfeck \& Juarez, 1988; Wulfeck, Bates, Juarez, Opie, Friederici, MacWhinney \& Zurif, 1989; Vaid \& Pandit, this issue).

(2) Performance deficits: The existence, strength and nature of the crosslinguistic differences uncovered in these studies lead to the conclusion that languagespecific knowledge (i.e. competence) is largely preserved in Broca's and Wernicke's aphasia, requiring an account of language breakdown based on deficits in the processes by which this preserved knowledge base is accessed and deployed (i.e. performance). This conclusion has led, in turn, to an expanded use of "on-line" or "real-time" experimental procedures that yield information about how patients from different language groups arrive at a correct or incorrect response in receptive and expressive language use (see especially Wulfeck, Bates \& Capasso, this issue; Friederici \& Kilborn, 1989).

(3) Selective vulnerability of morphology: Overlaid on these language differences, we find some evidence for a modified version of the Closed-Class theory of agrammatism, i.e. the idea that grammatical inflections and function words can be selectively impaired in aphasia. In these and other papers by the same research team, we have found evidence for closedclass impairments in production, comprehension and error detection - although the degree and nature of those impairments vary greatly from one language to another. In addition, these crosslinguistic studies have also helped to distinguish between those aspects of morphology that are "at risk" (e.g., case contrasts that are irregular and/or relatively difficult to perceive) and those that appear to be "protected" (e.g., case contrasts that are regular and/or relatively easy to perceive) within and across language types (see especially Friederici, Weissenborn \& Kail, this issue; Mac- 
Whinney, Osmán-Sági \& Slobin, this issue).

(4) Patient group similarities: The selective vulnerability of morphology described above is apparently not restricted to agrammatic Broca's aphasics. We have observed equivalent morphological deficits in the expressive language of fluent Wernicke's aphasics; receptive deficits appear in an even wider range of patient groups, including some patients who are neurologically intact (see especially Bates et al., 1987a; MacWhinney, Osmán-Sági \& Slobin, this issue). This suggests that closed-class items might be vulnerable to global forms of stress that are only indirectly related to the effects of focal brain injury (e.g., perceptual degradation; cognitive overload). Such findings point to the need for experiments that control for the contribution of a global reduction in perceptual and/or cognitive resources, in order to isolate those forms of grammatical impairment that are specific to particular types of aphasia from those that can be induced in normals under stressed or nonoptimal processing conditions (e.g., Kilborn, this issue).

(5) Similarity of lexical \& grammatical symptoms: Although morphology appears to be a quantitatively vulnerable domain, the grammatical symptoms displayed by these patients are qualitatively similar to their lexical (i.e. word-finding) symptoms (e.g., similar effects of frequency, complexity, semantic relatedness). These similarities are compatible with models in which lexical and grammatical forms are represented in a common format and/or accessed by a common set of processing mechanisms. This interpretation is still controversial, but it could be tested through detailed comparisons of lexical and grammatical processing, in languages that contrast markedly in the degree to which they rely on word order, inflections and/or lexical contrasts to accomplish the same communicative goals (see, for example, papers by Bates, Chen, Tzeng, Li \& Opie and by Chen \& Hung, this issue).

(6) Patient group differences: Although there are indeed more similarities than differences in the patterns of sparing and impairment observed in Broca's and Wernicke's aphasics, we have uncovered a set of contrasts that hold up across very different language types: differential success in the production of nouns and verbs (Bates, Chen, Tzeng, Li \& Opie, this issue), differences in the ability to exploit both grammatical and lexical redundancy (Bates et al., 1987a \& b), and differences in the nature of morpheme substitution errors (Bates, Friederici \& Wulfeck, 1988). The papers presented in this special issue were designed to explore these proposed "neurolinguistic universals" in greater detail, bringing us one step closer to a model of intrahemispheric organization that can handle universal and language-specific differences between syndromes.
In the next few pages, we will provide a brief summary of crosslinguistic evidence in support of these six conclusions, including a discussion of two competing theories that have guided all this work (i.e. the Competition Model, and the Closed-Class Theory of Agrammatism). Then we will end with a discussion of a serious methodological problem that confronts all researchers interested in applying the crosslinguistic method: the problem of patient selection across languages with radically different structural and statistical properties. Since this is a problem that can only be resolved by much more crosslinguistic research, we hope that this discussion will inspire other investigators to add to a growing body of comparative evidence on fluent and nonfluent aphasia across natural languages.

\section{OVERVIEW OF CROSSLINGUISTIC EVIDENCE}

Our own crosslinguistic aphasia project is built upon the theoretical, empirical, methodological and organizational foundations provided by 18 years of crosslinguistic research on normal adults and children by Bates and MacWhinney (Bates \& MacWhinney, 1987; MacWhinney \& Bates, 1989). The theory of language processing that has emerged from that work, i.e. the Competition Model, provides an interactive activation account of the quantitative and qualitative variations in sentence processing that are observed across languages, in normal speakers and aphasic patients. This model can be contrasted with the Closed-Class Theory of Agrammatism (Bradley, Garrett \& Zurif, 1980; Friederici, 1986; Kean, 1979 \& 1985), a modular account of grammatic impairment in aphasia that is based in part on Garrett's multilevel theory of sentence production and sentence comprehension in normal adults (e.g., Garrett, 1980). After several years of collaborative research by investigators in both "camps", we are now close to a fruitful compromise between these contrasting approaches to grammatical processing in normals and aphasics, integrating the relative contributions of linguistic experience (reflected in the crosslanguage contrasts observed in patients from the same diagnostic category) and neural specialization (reflected in patient group differences that hold up across language types).

Taken in their strongest and most interesting form, modular or disconnection theories of aphasia should predict broad differences between patient groups, with relatively little differentiation as a function of language type. Simply put, if a patient has lost the grammatical component that handles most if not all of the significant structural facts that define a natural language, then the same patient should (presumably) lose most of the performance characteristics that define a native speaker of that language. For example, the ClosedClass theory of agrammatism predicts a selective 
impairment of grammatical inflections and function words in Broca's aphasics, in comprehension and production. Under a strong interpretation of this model (i.e. a disconnection view), it is assumed that Broca's area plays a special role in grammatical representation and/or processing. Hence we should expect Broca's aphasia to result in a reduction or indeed a complete loss of crosslinguistic differences in the use of closed-class items; such differences should be largely preserved in Wernicke's aphasia, because the neural regions responsible for grammar are assumed to be intact in these patients.

The Competition Model predicts fewer differences between aphasic syndromes, but more differentiation as a function of language type. It provides two basic principles that predict crosslinguistic differences in the linguistic performance of patients from the "same" clinical category, and within-language similarities in the performance of patients with different forms of focal brain injury. Cue validity refers to the information value of a given phonological, lexical, morphological or syntactic form within a particular language (e.g., the availability and reliability of a particular word order type as a cue to semantic roles like agent, action and object). Cue cost refers to the amount and type of processing associated with the activation and deployment of a given linguistic form, when cue validity is held constant (e.g., the amount of memory required to store and compare agreement cues across the course of a sentence; the degree of perceptual difficulty posed by different types of case markers). These two principles (which can be quantified with some precision) co-determine the nature of linguistic representations in a particular language, and the nature of the dynamic process by which form and meaning are activated and mapped onto each other in real time. In this model, linguistic information is represented as a broadly distributed network of probabilistic connections among linguistic forms and the meanings they typically express (see also Hinton \& Shallice, 1989; Seidenberg, McClelland \& Patterson, 1987; Rumelhart \& McClelland, 1986). Linguistic rules are treated as form-meaning and form-form mappings that can vary in strength, so that the "same" rule may be stronger in one language than it is in another, as a function of crosslinguistic differences in the relative cue validity of equivalent linguistic forms (e.g., basic word order is "stronger" in English than it is in Italian; subject-verb agreement is "stronger" in Italian than it is in English). Different kinds of linguistic information (phonological, lexical, morphological, syntactic) are represented together in a common format, and the processes of mapping meaning onto form (in production), form onto meaning (in comprehension) and the process of evaluating the internal compatibility of two or more forms (e.g., grammaticality judgment) all involve graded activation (excitation and inhibition). Decisions about what to say or how to interpret the input emerge through a quantitative process of competition and conflict resolution within this broadly distributed and richly interconnected knowledge base. Applied to language processing in aphasia, the principle of cue validity makes the following prediction: The selective impairment of cues in comprehension, and the relative accessibility of forms in production, will reflect quantitative differences in the strength or probability of form-function and form-form mappings in the premorbid language of the patient. Simply put, this means that it should be very hard to eradicate Italian from Italians, Turkish from Turks, and so on, because the essential characteristics of one's native language are broadly represented and deeply engrained; they do not exist in an isolated "box" that can be selectively dissociated in aphasia.

The principle of cue cost mitigates and complements the predictions of cue validity. Because linguistic items (words, morphemes, phrase structure frames) can vary in their accessibility (i.e. perceivability, ease of articulation, degree of confusability with other items - see Bates \& Wulfeck, 1989a), a reduction in processing resources along any of the relevant dimensions (i.e. perception, attention, memory) may have selective effects on the speaker/listener's ability to use particular items in real time. Hence items that are equivalent in information value (cue validity) may be differentially spared or impaired, depending on the amount and type of processing they require (cue cost). The implications for aphasia are the following: Classes of linguistic information that are high in cue cost will be selectively impaired in all forms of aphasia; the same pattern of selective sparing and impairment may result from different forms of brain damage, and/or from global processing limitations in subjects who are neurologically intact. That is, hard things should be hard for everyone within a particular language; differences are a matter of degree. As currently formulated, the Competition Model contains no principles that would predict a systematic qualitative difference between patient groups (e.g., Broca's versus Wernicke's aphasia). To the extent that we find systematic patient group differences in the deficits observed within and across language types, the cue cost principles of the Competition Model must be modified.

Presumably, such modifications would involve postulating specific rather than general forms of cue cost, associated with damage to specific brain regions. A number of processing accounts of differential language breakdown that are compatible with the basic architecture of the Competition Model have emerged in the last few years, in response to findings that contradict disconnection theories (e.g., sensory vs. motor aphasia; grammar vs. semantics). Some of these new accounts include: (1) the suggestion that anterior and posterior 
lesions differ in their effect on processing speed (i.e. anterior lesions have a greater effect on rapid processes - Friederici \& Kilborn, 1989; Swinney, Zurif \& Nicol, 1989) and/or types of working memory (e.g., anterior lesions result in a "degraded trace" — Ostrin \& Schwartz, 1986); (2) the suggestion that anterior lesions have a selective effect on automatic aspects of language processing, while posterior lesions have a greater impact on controlled processing (Milberg \& Blumstein, 1981); (3) Posner's arguments for a differential anterior-posterior distribution in the basic components of attention (with differential effects on those aspects of language processing that are most dependent on anterior vs. posterior aspects of attention - Posner, Petersen, Fox \& Raichle, 1988); (4) the idea that anterior lesions result in a selectively greater reduction of excitation while posterior lesions tend to reduce inhibition - an old proposal (e.g., Goldstein, 1948) that has taken on new meaning in an era of neural network models, combined with an increased understanding of neural transmitters, their differential distribution in the brain, and their differential consequences for computation. Any of these proposed contrasts might result in qualitative differences in the performance deficits displayed by Broca's and Wernicke's aphasics (as defined below), without contradicting the assumption that linguistic knowledge (competence) is broadly distributed in the brain and largely preserved in patients with focal brain injury (see also Hinton \& Shallice, 1989; Linebarger, Schwartz \& Saffran, 1983; Seidenberg et al., 1987). The field of aphasiology appears to be moving toward a new theory of intrahemispheric organization. The languages, patient groups and experimental procedures represented in this special issue contribute to this effort.

In our crosslinguistic studies across the last 8-10 years, the Competition Model and the Closed-Class theory of agrammatism have been tested against basic comprehension and production data for Broca's aphasics, Wernicke's aphasics and a range of other patient groups, in Indo-European languages (English, Italian, German, Serbo-Croatian \& Spanish) that vary in the relative cue validity of word order and grammatical morphology. More recently, these results have been replicated and extended in three directions:

- a larger array of language types (including Hungarian, Chinese, Turkish, Hindi \& Kannada), from four different language families (Finno-Ugric, SinoTibetan, Ural-Altaic, Indo-European);

- a wider array of experimental techniques (e.g., realtime studies of grammaticality judgment - Wulfeck, Bates \& Capasso, this issue);

- a range of new and interesting control populations that help us to sort out global and specific cue cost factors (e.g., congenitally deaf individuals who are neurologically intact — Volterra \& Bates, 1989; normals under conditions of perceptual degradation or cognitive overload - Kilborn, this issue).

Given the array of contrasts studied across the last decade, we are now confident that our six basic conclusions about the nature of language breakdown are correct. These include (1) strong evidence that languagespecific lexical and grammatical knowledge is preserved in aphasia, interacting with (2) evidence for a selective "softening" of the patients' ability to make use of this knowledge, a processing deficit that is (3) most evident in the comprehension and/or production of grammatical inflections and function words. The first three findings are entirely compatible with the Competition Model, although they are also compatible with a probabilistic variant of the Closed-Class theory. In the same period we have also obtained important new information about the nature and extent of these processing deficits, leading to a compromise view of intrahemispheric organization for language. (4) The vulnerability of morphology is not restricted to Broca's aphasia (against the Closed-Class theory). (5) There are qualitative similarities between the morphological and lexical symptoms displayed by aphasic patients (against the Closed-Class theory). (6) There are subtle processing differences between Broca's and Wernicke's aphasia that hold up across language types: in noun vs. verb production; in the effects of cue convergence; in the nature of morpheme substitution errors (i.e. more use of high-frequency or unmarked forms in Broca's aphasia; more low-frequency or highly marked substitutions in Wernicke's aphasia). These differences are not compatible with the Competition Model in its original form, nor are they compatible with either of the major disconnection theories (sensory vs. motor; grammar vs. semantics); however, they are compatible with one or more of the processing accounts described above.

To provide background for the nine papers reported in this issue, let us briefly review crosslinguistic evidence in support of these six conclusions.

\section{(1) Cross-language contrasts}

The major rationale for crosslinguistic research is the search for quantitative and qualitative variations in the symptom patterns displayed by fluent and nonfluent aphasic patients. We have indeed found robust evidence for cross-language variation in both patient groups, in production, comprehension and grammaticality judgment.

Sentence production. Three published studies of sentence production in English, Italian and German patients provide background for new studies of sentence production using the same method in Turkish (Slobin, this issue), Hungarian (MacWhinney \& Osmán-Sági, this issue), and Chinese (Tzeng, Chen \& Hung, this issue). All these studies are based on a picture-description situation called the Given-New Task (Bates, Hamby \& Zurif, 1983; MacWhinney \& Bates, 
1978), which involves a series of three-picture cartoons in which one element varies while the remaining elements remain constant (e.g., a little girl is pictured eating an apple, then an ice cream, then a cookie). The picture triplets are designed to elicit intransitive, transitive, dative and locative structures, in a situation that restricts the range of semantic and pragmatic targets the patient might have in mind. In several of these studies, the Given-New data have been supplemented by free-speech results from a biographical interview. Both data sets have been transcribed and coded in the format specified by the Child Language Data Exchange System (CHILDES, MacWhinney \& Snow, 1985), modified to handle the special problems posed by adult aphasia data. We have used these data as the cornerstone for a new system called ALDES (Aphasic Language Data Exchange System, announced in Bates \& Wulfeck, 1989b), available to qualified researchers around the world (with proper controls to insure patient confidentiality).

Pragmatic effects on lexical and grammatical form. Building on an earlier study with English patients (Bates, Hamby \& Zurif, 1983), we have examined the effect of the given-new contrast on several aspects of linguistic expression in English, Italian and German patients (Wulfeck et al., 1989). Briefly stated, results suggest that Broca's and Wernicke's aphasics both retain sensitivity to the givennew contrast: in the decision about which elements in the picture to lexicalize (new) or omit (old), in the use of indefinite (new) vs. definite (old) articles, in the use of pronouns (which tend to be used to express old information, when they are used at all). Combining given-new data with biographical interviews, we have also shown that German and Italian patients are sensitive to an important crosslinguistic contrast called "the null subject parameter" (Rizzi, 1980). That is, German patients appear to know that subjects are obligatory in free-standing declarative sentences (producing subject pronouns most of the time even when the identity of the subject can be taken for granted); Italian patients appear to know that subjects can be omitted from free-standing declarative sentences in their language (when the identity of the subject is obvious from the context). These cross-language differences in subject omission are very large, transcending the smaller difference in subject omission that characterizes Broca's vs. Wernicke's aphasics within each language.

Word order. The first study of word order that we completed within our own crosslinguistic project (Bates, Friederici, Wulfeck \& Juarez, 1988) focussed on the order of basic sentence constituents in English, Italian and German patients, showing that canonical sentence order (Subject-Verb-Object, or SVO) appears to be preserved in both Broca's and Wernicke's aphasics. Indeed, some patients (particularly Broca's) appear to overuse basic SVO, as though this word order type provided a kind of "safe harbor" for sentence planning. Such overuse is only evident in languages that permit pragmatic word order variation; it could not be detected in a rigid word order language like English. Noncanonical word order patterns may be slightly impaired in languages that permit such options, but the degree to which this is true seems to depend on the frequency and utility of each word order variant. For example, Italian patients (including Broca's aphasics) do produce a number of pragmatically appropriate subjectfinal constructions (the most frequent noncanonical word order type in the language); a less frequent form of word order variation (with the object placed before the verb) appears in the speech of Wernicke's and normal controls, but seems to be avoided by Broca's aphasics. We conclude that canonical word order is preserved in aphasia, but there are variations in the "accessibility" of noncanonical word order options that vary by language and patient group.

Subsequent studies in other languages have replicated and extended this word order finding. The basic SOV word order of Turkish is clearly preserved in fluent and nonfluent aphasics (Slobin, this issue), and indeed may be overused by aphasic patients (especially Broca's) when these data are compared with the word order variations produced by normal controls. Further information comes from Hungarian (MacWhinney \& Osmán-Sági, this issue). Although it is sometimes argued that Hungarian is an SOV language, the situation is actually more complex. SOV order is used when the object of the verb is indefinite, while SVO order is preferred when the object is definite. Object definiteness is marked on the verb itself, creating an interesting interplay of pragmatic, morphological and syntactic factors. Hungarian patients produced a high proportion of both SOV and SVO in their picture descriptions, suggesting that canonical word order is preserved in aphasia even when there are two canonical options available. Furthermore, patients appear to retain the ability to coordinate word order and definiteness, in accordance with the rules of Hungarian (although there are some interesting strategies that patients adopt to "avoid" this situation, making use of legal options including article omission - see morphological production, below). Finally, SVO biases are also evident in the speech of our Chinese patients, although many patients (including Broca's) attempt to produce one or more of the legal word order alternatives in Chinese, struggling to provide the topic markers that are required for these alternative word order types (Chen, 1989; Chen, Bates \& Tzeng, 1990; Tzeng, Bates \& Wong, 1990; see discussion in Bates, Chen, Tzeng, Li \& Opie, this issue).

Grammatical morphology. We find consistent evidence that grammatical morphemes (bound and free) are selectively vulnerable in aphasia (see below), but this finding must be interpreted together with overwhelming evidence that Broca's and Wernicke's 
aphasics retain detailed and specific knowledge of the system of grammatical morphology in their language. For example, in our study of English, German and Italian patients (Bates, Friederici \&Wulfeck, 1988) we found a significant main effect of language in the proportion of function words to total words produced (i.e. higher proportions of function word use in German and Italian, lower proportions in English); this crosslinguistic pattern reached significance when Broca's, Wernicke's and normal controls were analyzed separately or together. We also found a large and consistent crosslanguage difference in the production of definite and indefinite articles. There are only three forms of the article in English, compared with nine forms marked for gender and number in Italian, and a much larger array of options marked for gender, number and case in German. On grounds of relative difficulty, we should expect article omission rates to be highest in German patients and lowest in English patients. However, on grounds of cue validity (i.e. the amount of information encoded in the article), we should expect the opposite finding: German < Italian < English on a measure of article omission. Results strongly favor the cue validity prediction: Even among the nonfluent Broca's aphasics, article omission averaged less than $15 \%$ in German and $25 \%$ in Italian, compared with an average rate of $70 \%$ omission in English. Patients did occasionally produce the wrong form of the article, but these error rates were quite low (e.g., 7\% in Italian and $16 \%$ in German, with similar error rates in both patient groups - see below); this means that patients produce the correct form in the overwhelming majority of cases, far more than we would expect if morphemes were generated randomly (as predicted by Grodzinsky, 1986).

Further evidence for the preservation of morphological knowledge (as opposed to performance - see below) is provided in our studies of the production of case inflections in Turkish (Slobin, this issue) and Hungarian (MacWhinney \& Osmán-Sági, this issue), and in a study of one small but intricate domain of function word production in Chinese, the system of nominal classifiers (Tzeng, Chen \& Hung, this issue). Errors do occur, but the probability of an error is greatly conditioned by cue validity (i.e. information value) and cue cost (i.e. relative frequency, salience, pronounceability), and patients are right more often than they are wrong. These findings are difficult to reconcile with a disconnection view of closed-class impairments in aphasia.

We should also point out some systematic findings regarding the nature of those morphological errors that do occur in expressive language. First, although omission errors are more common in Broca's aphasics compared with Wernicke's, morpheme substitution errors occur in both forms of aphasia. It is not the case that Broca's aphasics regularly omit free-standing function words; rather, the patient's decision to omit an item or try to find the correct form appears to be a partial function of the cue validity or importance of that form in the patient's native language (e.g., the above data on article omission in English, German and Italian). In other words, the patterns of omission and substitution observed in Broca's and Wernicke's aphasia reflect the patients' detailed knowledge of legal options and information demands in their language. Second, certain types of logically possible errors are rare or nonexistent in our data. There is virtually no evidence for errors that violate principles governing the order of bound morphemes within a word, or the order of function words within a noun phrase. Patients simply do not make mistakes like "Dog the" or "ingwalk", even though errors of this kind are logically possible (particularly in a language like Hungarian, where a noun can take up to 3-4 suffixes in a required order). There is also very little evidence in our Turkish or Hungarian data for errors of vowel harmony, an aspect of morphology that is conditioned by phonological factors spanning more than one word. Although these findings are drawn from sentence production data, they can be used to guide studies of online grammaticality judgment, to determine the extent to which sensitivity to errors in receptive processing mirrors the error patterns that occur in spontaneous speech (see Wulfeck et al., this issue).

Sentence comprehension. Three previous studies of sentence comprehension provide background for the papers in this issue: one on Broca's and Wernicke's aphasics in English, German and Italian (Bates et al.,1987a), and two examining the interaction of grammatical cues in Serbo-Croatian Broca's and anomic aphasics (Smith \& Mimica, 1984; Smith \& Bates, 1987). All of these experiments were based on the same simple off-line procedure (i.e. the procedure applied by MacWhinney et al., this issue, and by Vaid \& Pandit, this issue; see also Chen et al., 1990, for Chinese). In this task, patients are asked to interpret simple sentences by acting them out with small toy objects (e.g., "Show me THE COW IS KICKING THE PENCIL"). The sentence stimuli represent competing and converging combinations of semantic cues (i.e. the contrast between animate and inanimate objects), syntactic cues (i.e. standard and nonstandard word orders) and morphological cues (presence/absence of case markers on the first or second noun in case-inflected languages; presence/absence of subject-verb agreement or object marking on the first or second noun in languages with agreement markers). This design permits us to assess the hierarchy of importance of lexical, morphological and syntactic cues to agent/object relations in each language, a direct test of the cue validity predictions of the Competition Model. (Because the notion "percent correct" is meaningless in such a competition design, the dependent variable for all analyses is "percent choice of the first noun as agent").

In the Bates et al. study, Broca's and Wernicke's 
aphasics within each language group displayed language-specific patterns in their use of word order (English > German > Italian), semantic contrasts (German > Italian > English) and agreement morphology (Italian > German > English). Although use of grammatical morphology in sentence comprehension appeared to be impaired in all aphasic groups relative to normal listeners in that language (see below), patients were still performing above chance in the use of morphological information (particularly in richly inflected languages). Use of canonical word order information showed no deterioration in any language or patient group; in fact, many of our German and Italian patients (fluent and nonfluent) used canonical word order more than normal controls, compensating for reductions in the use of grammatical morphology — a finding that mirrors our results for sentence production (above). Use of semantic information is also in the normal range (and varies from one language to another for aphasic patients, as it does for normals). In short, the hierarchy of importance of cues to sentence meaning from one language to another reflects differences in cue validity; these differences are preserved in the data for fluent and nonfluent aphasics, although the accessibility of some cues (especially grammatical morphology) appears to be reduced.

Grammaticality judgment. An influential study by Linebarger et al. (1983) showed that so-called agrammatic Broca's aphasics can make subtle judgments of grammaticality. This important finding has now been replicated in several laboratories, including our own, and it appears to hold up even when patients are asked to make their judgments "on line" (Wulfeck, 1987; Wulfeck, 1988; Wulfeck \& Bates, 1990; Wulfeck et al., this issue; Lukatela, Crain \& Shankweiler, 1988; Shankweiler, Crain, Gorrell \& Tuller, 1989). In Wulfeck et al. (this issue), we have explored crosslinguistic differences in the detection of grammatical violations as a new domain in which to test the basic cue validity and cue cost assumptions of the Competition Model. Italian and English Broca's aphasics and normal controls were presented with sentences in which verb auxiliaries and determiners are manipulated in two ways to produce an ungrammatical sentence: Either the element is substituted to produce an incorrect form of agreement (e.g., "The girl is selling books..." $\nRightarrow$ "The girl are selling books..."), or the same element is moved downstream ("The girl is selling books..." $\rightleftarrows$ "The girl selling is books...."). Although both English and Italian normals show sensitivity to both types of violations (responding at ceiling), their decision times are quite different on this task, in keeping with other evidence on the relative importance of word order vs. morphology in these two languages: English normals are particularly quick and efficient at detecting errors of item ordering, while Italian normals are relatively slow in detecting order violations but perform optimally in the detection of errors involving morphological substitution. This crosslinguistic difference is preserved in the error and reaction time data of English and Italian Broca's aphasics, but to a much smaller degree (in line with our argument that morphology is selectively vulnerable in aphasia - see below).

\section{(2) Performance deficits and activation models}

The detailed crosslinguistic variations that we just described constitute ipso facto evidence in favor of the view that grammatical and lexical knowledge (i.e. competence) is largely preserved in Broca's and Wernicke's aphasia. These facts argue in favor of a performance account, i.e. a theory that attributes selective patterns of sparing and impairment to deficits in the processes by which linguistic knowledge is accessed and deployed. In addition to these facts, we have found other lines of evidence to support a particular kind of processing model, an interactive activation approach in which cues of varying strength combine to determine the probability of a correct or incorrect response.

First, this approach is supported by the systematically graded nature of the deficits we see in both production and comprehension (i.e. a direct relationship between probability of error and strength of a given linguistic form in a particular language).

Second, it is supported by evidence on the way that cues combine in receptive processing tasks. For example, Smith and Bates (1987) have examined the interactions among three different grammatical cues to sentence meaning in Serbo-Croatian: word order (a small but significant tendency for normal listeners to choose the first noun as agent), accusative case marking (to indicate the object role), and gender agreement (to indicate the subject role). In morphologically ambiguous sentences (no case or gender - sentences which do occur in this language), patients showed a weak tendency to choose the first noun; when this bias was reinforced by the presence of an agreement cue, performance did not improve (as though the patients were unable to detect gender marking); when word order and case are presented together (with no gender marking), performance was significantly better but still far below normal levels. However, when all three grammatical cues were presented together (ORDER + CASE + GENDER), Broca's aphasics were able to interpret sentences at close to normal levels. In other words, these three cues are combining in a nonlinear fashion, as though all three were needed to boost response above some performance threshold - a threshold that has been raised to abnormally high levels as a result of focal brain injury.

We have similar results on cue convergence in our study of sentence comprehension in English, Italian and 
German aphasics (Bates et al., 1987a), although these convergence effects are particularly marked in Broca's aphasics (a point to which we will return below). These results place previous studies of receptive agrammatism in a new light. The existence of receptive agrammatism in patients who are "clinically normal" in comprehension has usually been explained by suggesting that these patients use pragmatic and semantic information to circumvent their grammatical limitations in a real-life situation. Our studies suggest instead that Broca's aphasics can use any form of redundancy (including grammatical redundancy) to overcome their performance deficits. This conclusion is compatible with interactive activation models, but it is difficult to reconcile with theories that explain agrammatism by postulating a disconnection between linguistic modules.

\section{(3) Selective vulnerability of morphology}

We have already described evidence suggesting that grammatical morphology is selectively vulnerable in aphasia, compared with pragmatic or syntactic aspects of linguistic performance. This finding is also confirmed in the Wulfeck et al. study of error detection (i.e. selectively greater loss of sensitivity to agreement vs. ordering errors in both Italian and English aphasics, although agreement sensitivity was still significantly greater among the Italians). Given the degree to which morphological knowledge is preserved in the same patients, it is all the more surprising that morphological processing deficits are so pervasive across different language types. We were particularly surprised to find severe deficits in the use of case morphology in our study of sentence comprehension in Turkish and Hungarian (MacWhinney et al., this issue), because case morphemes are extremely high in information value in both these languages, and because errors of case marking are relatively rare in the expressive language of Turkish and Hungarian aphasics (in line with predictions based on cue validity Slobin, this issue; MacWhinney \& Osmán-Sági, this issue). To account for this pattern, we suggest that the processing costs associated with grammatical morphology may be particularly high in receptive language - a conclusion that is bolstered by findings in the next category.

\section{(4) Morphology is vulnerable across patient groups}

First, we have found no evidence to support the idea that Broca's aphasics are unique in the inability to process closed-class morphemes. In richly inflected languages, rates of morpheme substitution errors are remarkably similar for Broca's and Wernicke's aphasics (Bates, Friederici \& Wulfeck, 1988; MacWhinney \& Osmán-Sági, this issue; Slobin, this issue; Tzeng, Chen \& Hung, this issue). For example, German
Broca's aphasics produce the wrong form of the article $16 \%$ of the time, compared with a $17 \%$ substitution rate for German Wernicke's. The same is also true in Chinese: Broca's and Wernicke's aphasics both make substitution errors on noun classifiers (a complex class of function words in a language with relatively few closed-class items, and no inflectional morphology of any kind). We conclude that the contrast between agrammatism (attributed to Broca's aphasia) and paragrammatism (attributed to Wernicke's aphasia) has been greatly exaggerated, due to the fact that morpheme substitution errors are relatively ambiguous and difficult to detect in English (for a detailed discussion, see Bates $\&$ Wulfeck, 1989a \& b). There are subtle differences in the errors produced by Broca's and Wernicke's aphasics (see below), but morphology is the domain that is most prone to error in both these patient groups.

Second, we have found evidence for receptive agrammatism in patients who show no signs of grammatical impairment in their spontaneous speech. For example, we have administered the sentence comprehension task described above to a range of Italian patient groups including anomics, right-hemisphere patients, neurological patients without focal brain injury, and some nonneurological patients from the orthopedic ward (Bates et al., 1987a; Bates \& Wulfeck, 1989b; Smith \& Bates, 1987); all showed significant and selective impairments in the ability to use subjectverb agreement as a cue to sentence meaning - deficits that were in many cases just as severe as the deficits shown by Broca's and Wernicke's aphasics. The same receptive/expressive dissociation occurs in our studies of Turkish and Hungarian (MacWhinney et al., this issue), showing up in patients who were classified as simple anomics, and in a subset of nonneurological patient controls - despite the fact that cue validity is a powerful cue to meaning for normal adults in both these languages, used reliably by small children between 2-3 years of age. This cannot be a simple effect of age or education, because healthy controls matched for age and education perform like college students on the same sentence comprehension task. Instead, it suggests that selective impairments of grammatical morphology may result from global perceptual and/or cognitive limitations above and beyond the specific effects of focal brain injury.

We have tried to disentangle global vs. specific causes of morphological breakdown, in several ways. For example, to study the effect of perceptual limitations on production and comprehension of morphology, we have carried out studies of congenitally deaf but neurologically intact speakers of Italian (Volterra \& Bates, 1989). These subjects also display a selective impairment in their ability to comprehend and produce grammatical inflections and function words. In act, we have found a striking impairment in the use of grammatical morphemes by a highly educated and successful deaf woman who is indistinguishable from 
normal in lexical and syntactic aspects of her written Italian, demonstrating near-perfect knowledge of her grammar in off-line metalinguistic tasks. At the same time, we have also uncovered some interesting differences between deaf subjects and aphasic patients in the kinds of errors produced in written and spoken Italian. For example, a much higher proportion of errors in the deaf involve free-standing function words (rather than bound inflections). Also, gender errors are extremely rare in the deaf but quite common in aphasic patients, suggesting that perceptual limitations may have less of an effect on morphemes that are an inherent part of the word (e.g., gender). Taken together, these results support the idea that perceptual limitations have a selectively greater impact on the use of grammatical morphology - one factor (but probably not the only factor) in receptive and expressive agrammatism.

Additional evidence for the selective impact of global perceptual and/or cognitive factors on morphology comes from our pilot studies testing normals under adverse processing conditions. For example, Kilborn (this issue) has conducted a groundbreaking study of German- and English-speaking college students in an on-line version of our sentence interpretation task, using auditory stimuli that are partially masked by "pink noise" (i.e. random noise restricted to the speech band). The noise manipulation has virtually no effect on English subjects: There is no reduction in the strength of word order as a cue to agent/object relations (although reaction times are slowed overall), and little effect on agreement morphology (which is largely ignored by English subjects even under optimal conditions). However, German subjects display a marked and very specific reduction in the use of agreement morphology (a very strong cue for Germans under normal conditions), with virtually no effect on animacy or word order mirroring our results with German aphasics.

We are certainly not trying to claim that all aphasic symptoms can be reduced to normal processing under some form of stress. However, in order to separate the effects of global stress from specific effects of focal brain injury, we believe that the usual normal control conditions used in neuropsychological research must be supplemented by observations of normals operating under stressed conditions. Global stress controls should include what Norman \& Bobrow (1975) call datalimited processes (e.g., auditory stimuli degraded by a partial noise mask) and resource-limited processes (e.g., cognitive overload in a dual task paradigm). Indeed, such manipulations may become standard in the field as aphasia researchers make increased use of on-line processing tasks of the sort described in this special issue.

\section{(5) Similarity between lexical and} grammatical symptoms

Although the closed class appears to be quantitatively more vulnerable than other aspects of language processing, we have also found evidence for qualitative similarities in the lexical (word-finding) and grammatical symptoms displayed by aphasic patients similarities that are particularly clear in spontaneous speech by speakers of a richly inflected language (Bates, Friederici \& Wulfeck, 1988; MacWhinney \& OsmánSági, this issue; Slobin, this issue). Examples include the following.

(a) There are frequency and/or markedness effects on the production of grammatical morphemes (e.g., a bias toward the nominative in case-inflected languages), and in the production of whole sentence frames (e.g., a bias toward canonical word order in all the languages studied, and a bias toward more frequent noncanonical word order variations); these findings resemble well-known effects of frequency in the production of content words.

(b) Patients who are struggling to produce the right function word in an obligatory slot (e.g., production of articles in German) often go through a process of successive approximation and self-correction that is highly reminiscent of the word-finding episodes that are so often reported for both fluent and nonfluent aphasics (e.g., "(die...der...das...die...den)..den Hund").

(c) There are effects of semantic relatedness in morpheme production errors, in those languages in which it is possible to rank morphemes along a semantic gradient (e.g., substitution of closely related locative suffixes in Hungarian - MacWhinney \& Osmán-Sági, this issue). This result is similar to the effects of semantic relatedness that are so often seen when a patient substitutes one content word for another (i.e. semantic paraphasias).

(d) Grammatical structures appear to be affected by "priming" effects (i.e. a build-up of contextual information), similar at some level to the priming effects that are known to occur in lexical access (see also Bock, 1986; Lukatela, Kostic, Feldman \& Turvey, 1983).

Although these findings are certainly not conclusive, they are compatible with the predictions of the Competition Model (and other interactive activation models), and constitute a major area for exploration in future crosslinguistic research, through detailed comparisons of lexical and grammatical processing, varying predictability (contextual buildup), frequency and semantic relatedness in both domains.

\section{(6) Patient group differences}

Finally, there are several areas in which we find consistent differences between Broca's and Wernicke's aphasics in our studies to date, beyond the diagnostic criteria that we used to define these groups in the first place (see below). These differences are subtle, but they appear to hold up across different language types, serving as "neurolinguistic universals" that may be particularly informative as our field moves toward a new 
theory of intrahemispheric organization for language.

(a) Redundancy. There are differences in the degree to which Broca's and Wernicke's aphasics are able to exploit converging sources of information in a receptive language task, i.e. the redundancy effects described above in Serbo-Croatian (Smith \& Bates, 1987) and in English, Italian and German (Bates, Friederici \& Wulfeck, 1987a). This pattern is compatible with the idea that Broca's aphasics suffer from "under-excitation" (requiring more information to reach threshold), while Wernicke's suffer from "underinhibition" (so that additional information activates too many associates, effectively doing more harm than good).

(b) Frequency/Markedness. There are differences in the nature of the morphological substitution errors produced by each group, reflecting what may be a conscious or unconscious difference in the underlying strategies that govern sentence planning in these patients. Nonfluent patients tend to avoid contexts that require production of a difficult morphosyntactic structure; when they do make mistakes, they tend to substitute a simpler, more frequent and/or less marked form. Fluent patients do not seem to have this kind of control over their own speech; they barge ahead and attempt complex constructions, making a less systematic array of substitution errors (including cases in which a lowfrequency item is substituted for the base form). These differences are compatible with (for example) a proposal by Milberg, Blumstein \& colleagues that controlled aspects of processing are spared in Broca's aphasia, with automatic processes spared to a greater extent in Wernicke's (e.g., Blumstein \& Milberg, 1983; Milberg \& Blumstein, 1981).

(c) Form class. In Bates, Chen, Tzeng, Li \& Opie (this issue), we have replicated a selective dissociation between action naming (impaired in Broca's aphasia) and object naming (impaired in Wernicke's aphasia). Although this difference has been reported by other investigators (e.g., Miceli, Silveri, Romani \& Caramazza, 1989; Saffran, Berndt \& Schwartz, 1989), crosslinguistic studies have helped to eliminate the hypothesis that verb problems are a byproduct of the fact that verbs carry more grammatical marking, because the same noun/verb dissociation between Broca's and Wernicke's aphasics appears in Chinese (where there are no inflections of any kind on nouns or verbs) and Hungarian (where nouns and verbs both require extensive morphological marking - Osmán-Sági, 1990). Furthermore, a particularly interesting and informative variant of the noun/verb problem appears in our data for Chinese, a language in which many words are compounds made up of a verbal element and a nominal element (e.g., the verb "to read", which can be translated literally as LOOK-BOOK). In their attempts to produce such compound words, Chinese Broca's tend to omit or substitute the verbal component, while
Wernicke's err more often on the nominal component. As elaborated in more detail by Bates et al. (this issue), these facts suggest that the noun/verb dissociation must be explained in lexical and/or semantic terms, a finding with implications for localization of function that transcend either a comprehension/production or a grammar/semantics account of the two aphasias.

To summarize, crosslinguistic research has added immeasurably to our understanding of universal and language-specific symptom patterns in aphasia. These results have forced a compromise between two contrasting theories of grammatical impairment, and they have opened up a whole new list of questions that would be difficult to answer within any single language (for example, English). We believe that the crosslinguistic method holds great promise for the future of aphasiology. However, it also presents some serious methodological problems that must be considered before we proceed.

\section{THE PROBLEM OF PATIENT SELECTION AND COMPARABILITY OF PATIENTS ACROSS LANGUAGE TYPES}

In the studies presented within this special issue, we have focussed on Broca's and Wernicke's aphasia, in comparison with a range of control populations. These two groups were chosen because (1) they both display forms of grammatical impairment that are of major interest in a crosslinguistic study, and (2) differences between these groups are correlated (albeit imperfectly) with anterior and posterior lesion sites, yielding information that is relevant to a characterization of intrahemispheric organization for language. However, because we have elected a Patient Group by Language Group design $^{1}$, we must ask ourselves whether it is

\footnotetext{
${ }^{1}$ Obviously we have taken a stand in favor of group studies. For reasons that we have outlined in considerable detail in two methodological papers (Bates, McDonald, MacWhinney \& Appelbaum, 1991; Bates, Appelbaum \& Allard, 1991), we disagree with arguments against group studies offered by Caramazza and his colleagues (e.g. Caramazza, 1986). Although individual case studies play an important role in aphasia research, these studies can only inform us about those patterns of language sparing and impairment that are possible within a given language. Case studies cannot tell us which patterns are likely or typical within and between language types. To test the competing hypotheses that we have described here against a cross-linguistic data base, we need information of the latter type. Indeed, we are quite concerned that our own group studies are not large enough, since results are often based on samples of only $4-10$ patients within a particular Language X Patient cell. This is one reason why we are interested in the establishment of a computerized data exchange system that will permit researchers in different language communities to share free-speech data.
} 
possible to select equivalent or even vaguely comparable groups of patients when the languages in question vary radically along structural and statistical dimensions that are central to a definition of "agrammatism", "paragrammatism" or (for that matter) grammatical impairment in any form.

To clarify the point, consider the contrasts that hold between just two of the languages represented in this special issue, Chinese and Turkish.

Chinese has what may be the most austere system of grammatical morphology in the world. There is essentially no bound morphology in this language, i.e. no marking for gender, number or tense, no agreement phenomena, indeed no verb conjugations or noun declensions of any kind. The language does provide a set of free-standing function words, but almost all of these words are homophonous with single-syllable content words that have a related meaning (e.g., to indicate that an act has been completed, one adds a particle after the verb that is equivalent in form and meaning to the word for "finished", as in "EATFINISHED"). Hence the line between closed-class and open-class words is much less obvious in Chinese than it is in other language families. Furthermore, those function words that do exist are obligatory only in particular discourse contexts. As a result, sentences with no function words and (of course) no bound morphemes of any kind can be completely grammatical in this language. It is fair to say that normal Chinese speech has many of the properties that characterize the "telegraphic" speech of so-called agrammatic aphasics in English!

Turkish stands at the opposite extreme: a caseinflected language with an extremely rich and regular set of bound morphemes for verbs, nouns, pronouns and several other elements. An entire sentence may consist of no more than one or two richly inflected words, each inflection standing in a particular position within an ordered string of prefixes or suffixes around a root word. Slobin (this issue) demonstrates that these inflections are remarkably well preserved in the speech of both fluent and nonfluent Turkish aphasics. In other words, Turkish Broca's aphasics simply do not produce telegraphic speech. For that matter, as Slobin notes, Turkish 2-year-olds do not produce telegraphic speech either. Indeed, telegraphic speech is not even used in Turkish telegrams!

How on earth could we possibly hope to "match" patients for severity or type of aphasia across languages that differ so radically in their basic structure? Obviously it would be sheer folly to match Chinese and Turkish patients for mean length of utterance, number of words per minute, or any other straightforward metric. For the same reasons, it would be most unwise to rely on standardized scores from the "same" aphasia test. To be sure, standard tests like the Boston
Diagnostic Aphasia Examination (Goodglass and Kaplan, 1983) have been translated and adapted in many of the languages represented within our crosslinguistic research. But adaptation and norming are not the same thing. We have no way of knowing at this time whether the "same" score means the "same" thing in English, Turkish or Chinese, because these powerful structural and statistical differences between languages are not taken into account when standardized tests are translated from one language to another.

To illustrate the same point with a less exotic example, we know from our previous work on English, German and Italian (Bates, Friederici and Wulfeck, 1988) that Italian and German Broca's aphasics tend to produce a much larger number of function words than their English counterparts. As we noted earlier, German patients typically omit the article before the noun no more than 5-20\% of the time, compared with an average omission rate of $70 \%$ in our English sample. Bates et al. attribute this crosslinguistic difference to an effect of cue validity, i.e. to the fact that the case-marked article carries crucial information of agent-object relations in German, while the article carries much less information and hence can be omitted with relatively little communicative loss in English. Of course, there is an alternative interpretation: It is possible that this difference derives from a failure to match subjects over languages, i.e. we have accidentally selected mild German aphasics and compared them with English patients who are more seriously impaired. However, if that were the case, shouldn't we expect similar differences in severity along all linguistic dimensions? And yet our English patients were not more impaired than their German counterparts in the use of canonical word order - a much more important aspect of grammar in English.

In the same vein, our Italian patients stand between their German and English counterparts in rate of article omission. Again, we could attribute this to an accidental difference in severity level in our two language groups. And yet a very different profile is observed in omission of the sentence subject: Subject omission is clearly much more common in Italian patients than it is in German or in English (Wulfeck et al., 1989). This difference is best explained by the fact that subject omission is a legal option in Italian (e.g., it is possible to say "Is going to the store" or "Is raining"); the same option is not permitted in German or in English. In short, if all the crosslinguistic differences that we have observed to date were due to random differences in severity over language groups, then it would be difficult to explain why these differences invariably line up in the predicted languagespecific direction.

This trend is comforting, but it does not make the problem of patient-matching disappear. In principle, it should be possible to match patients for their relative severity, on a scale that is calibrated differently for each 
individual language. With a sufficiently large body of norming information in each language group, we could match patients for their degree of deviation from normal in their particular language - a procedure that takes crosslinguistic differences in amount and type of grammatical marking into account. For example, it may turn out to be the case that a severely impaired Italian Broca's aphasic (i.e. a patient in the bottom tenth percentile for Italian) omits bound morphemes at a $50 \%$ level, comparable to omission rates for a mildly impaired English Broca's aphasic (i.e. a patient at the 50th percentile for English). We believe that percentile matches of this sort will ultimately prove to be the correct solution to the problem of patient selection and patient matching in crosslinguistic research. Unfortunately, the data base that is necessary to develop such percentile scores still does not exist (but see Paradis, 1987, for some important steps in this direction). Until a large crosslinguistic data base becomes available, we must be satisfied with an interim solution to the problem.

In our own crosslinguistic project, we have proceeded as follows. Patients are defined on behavioral grounds, according to a set of classic definitions that are recognized by clinicians in all the participating language communities (despite wide variations in the way these symptoms are realized from one language to another). Broca's aphasics are defined as nonfluent patients who display an abnormal reduction in utterance length and sentence complexity, with marked errors of omission and/or substitution in grammatical morphology; comprehension abilities appear to be normal in free conversation. By contrast, Wernicke's aphasics are defined as patients who produce fluent or hyperfluent speech with an apparently normal melodic line; these patients typically display serious word-finding difficulties, with semantic and/or phonological paraphasias; comprehension abilities are clearly impaired in free conversation. In all the languages under study, Wernicke's aphasics can be distinguished from (for example) anomics, i.e. fluent patients who display word-finding problems in free-speech and confrontation naming, in the absence of severe paraphasias or paragrammatism, and in the presence of normal comprehension abilities in free conversation. Because there are still no reliable grounds for a percentile-based match, we define patient groups within each language, according to their fit to one of two prototypes used by neurologists and speech pathologists in that community. For example, a prototypic Broca's aphasic would show reduced fluency and phrase length, and a tendency toward omission of functors (relative to normals in that language). Hence patients are matched across languages in the sense that they represent different degrees of deviation from a prototype developed out of observed variation within each language group. This permits us to compare the "best" and the "worst" patients across languages, as well as those who fit the mean. This is, of course, the logic behind percentile scores - and may eventually lead to cross-language percentile matching when enough cases have accu-mulated within each language group to permit the development of comparable aphasia norms.

Note also that we do not attempt to match patients by lesion type, for two reasons: (1) neural imaging is not always available, nor are the radiological facilities comparable from one site to another (e.g., San Diego, Rome, Taiwan and Budapest); (2) there are imperfect correlations among lesion site, lesion size and behavioral syndrome, exceptions that might (for all we know right now) interact in unknown ways with language type. However, we include all available neurological information in our patient archives; within some language and patient categories, we will soon have enough cases to permit post hoc analyses of the relationship between lesion type and symptom patterns, within and across language groups.

At each of the four research sites, neurologists and speech pathologists throughout the community refer patients who (in their clinical judgment) fit one of the above diagnoses. These diagnoses are accompanied by neurological records (including CT scans in many cases), together with the results of those standard aphasia batteries that are used at each research site. To eliminate the possibility that a patient has changed status since the diagnosis provided at referral, we screen all patients in a biographical interview administered and recorded prior to testing. In addition, we exclude all patients with one or more of the following conditions: history of multiple strokes; significant hearing and/or visual disabilities; severe gross motor disabilities; severe motor-speech involvement such that less than $50 \%$ of subject's speech attempts are intelligible; evidence that subject is neurologically or physically unstable and/or less than 3 months post onset.

This is our solution for the moment. Meanwhile, as we noted earlier, members of our research team have begun to transcribe and code their free-speech data in accordance with a modification of the coding scheme developed by the Child Language Data Exchange System (CHILDES, MacWhinney \& Snow, 1985). These records are being placed in a computer data base called ALDES (Aphasic Language Data Exchange System), a system that will be open to all interested investigators (Bates \& Wulfeck, 1989b). Eventually, we hope that other investigators will contribute to the ALDES database, providing a base of free-speech data that is large enough for the development of crosslinguistic norms.

With that note of warning, and accompanying message of hope, let us now turn to the nine substantive contributions by our crosslinguistic collaborators. 


\section{REFERENCES}

Bates, E., Appelbaum, M., \& Allard, L. (1991). Statistical constraints on the use of single cases in neuropsychological research. Brain and Language, 40, 295-329.

Bates, E., Chen, S., Tzeng, O., Li, P., \& Opie, M. (1991). The noun-verb problem in Chinese aphasia. To appear in a special issue on crosslinguistic aphasia in Brain and Language.

Bates, E., Friederici, A., \& Wulfeck, B. (1987a). Comprehension in aphasia: A crosslinguistic study. Brain and Language, 32, 19-67.

Bates, E., Friederici, A., \& Wulfeck, B. (1987b). Grammatical morphology in aphasia: Evidence from three languages. Cortex, 23, 545-574.

Bates, E., Friederici, A., \& Wulfeck, B. (1988). Grammatical morphology in aphasia: A reply to Niemi et al. Cortex, 24, 583-588.

Bates, E., Friederici, A., Wulfeck, B., \& Juarez, L. (1988). On the preservation of word order in aphasia: Cross-linguistic evidence. Brain \& Language, 33, 323-364.

Bates, E., Hamby, S., \& Zurif, E. (1983). The effects of focal brain damage on pragmatic expression. Special issue on brain and language (Doreen Kimura, Ed.). Canadian Journal of Psychology, 37, 59-63.

Bates, E., \& MacWhinney, B. (1987). Competition, variation and language learning. In B. MacWhinney (Ed.), Mechanisms of language acquisition. Hillsdale, NJ: Erlbaum.

Bates, E., McDonald, J., MacWhinney, B., \& Appelbaum, M. (1991). A maximum likelihood procedure for the analysis of group and individual data in aphasia research. Brain and Language, 40, 231-265.

Bates, E. \& Wulfeck, B. (1989a). Crosslinguistic studies of aphasia. In B. MacWhinney \& E. Bates (Eds.), The crosslinguistic study of sentence processing. New York: Cambridge University Press.

Bates, E. \& Wulfeck, B. (1989b). Comparative aphasiology: A cross-linguistic approach to language breakdown. Aphasiology, 3, 111-142 and 161-168.

Blumstein, S. \& Milberg, W. (1983, October). Automatic and controlled processing in speechlanguage deficits in aphasia. Symposium on Automatic Speech. Abstracts of the 21st Annual Meeting of the Academy of Aphasia, Minneapolis.

Bock, K. (1986). Syntactic persistence in language production. Cognitive Psychology, 18, 355-387.

Bradley, D., Garrett, M., \& Zurif, E. (1980). Syntactic deficits in Broca's aphasia. In D. Caplan (Ed.), Biological studies of mental processes. Cambridge, MA: MIT Press.

Caramazza, A. (1986). On drawing inferences about the structure of normal cognitive systems from the analysis of patterns of impaired performance: The case for single-patient studies. Brain and Cognition, 5, 41-66.

Chen, S. (1989, April). On grammatical deficits in Chinese aphasia. Abstracts of the 18th Annual Linguistics Symposium. University of Wisconsin, Milwaukee.

Chen, S., Bates, E., \& Tzeng, O. (1990, March). Sentence interpretation of Chinese aphasics. Abstracts of the Second Language Research Forum. University of Oregon, Eugene.

Friederici, A. (1986). Autonomy and automaticity: Accessing function words during sentence comprehension. In G. Denes, C. Semenza, P. Bisacchi \& E. Andreewsky (Eds.), Perspectives in cognitive neuropsychology. Hillsdale, NJ: Erlbaum.

Friederici, A. \& Kilborn, K. (1989). Temporal constraints on language processing in Broca's aphasia. Journal of Cognitive Neuroscience, 1 , 262-272.

Friederici, A., Weissenborn, J., \& Kail, M. (1991). Pronoun comprehension in aphasia: A comparison of three languages. To appear in a special issue on crosslinguistic aphasia in Brain and Language.

Garrett, M. (1980). Levels of processing in sentence production. In B. Butterworth (Ed.), Language production: Vol. 1. Speech and talk. New York/London: Academic.

Goldstein, K. (1948). Language and language disturbances: Aphasic symptom complexes and their significance for medicine and theory of language. New York: Grune \& Stratton.

Goodglass, H. \& Kaplan, H. (1983). Boston Diagnostic Aphasia Examination (2nd ed.). Philadelphia: Lea and Febiger.

Grodzinsky, Y. (1986). Language deficits and the theory of syntax. Brain and Language, 27, 135159.

Hinton, G.E., \& Shallice, T.(1989). Lesioning a connectionist network: Investigations of acquired dyslexia. (Tech. rep. CRG-TR-89-30). University of Toronto.

Kean, M.-L. (1979). Agrammatism: A phonological deficit? Cognition, 7, 69-84.

Kean, M.-L. (Ed.). (1985). Agrammatism. New York: Academic Press.

Kilborn, K. (1991). Selective impairment of grammatical morphology due to induced stress in normal listeners: Implications for aphasia. To appear in a special issue on crosslinguistic aphasia in Brain and Language.

Linebarger, M., Schwartz, M., \& Saffran, E. (1983). Sensitivity to grammatical structure in so-called agrammatic aphasics. Cognition, 13, 361-392. 
Lukatela, K., Crain, S., \& Shankweiler, D. (1988). Sensitivity to inflectional morphology in agrammatism: Investigation of a highly inflected language. Brain \& Language, 33, 1-15.

Lukatela, G., Kostic, A., Feldman, L., \& Turvey, M. (1983). Grammatical priming of inflected nouns. Memory and Cognition, 11, 59-63.

MacWhinney, B. \& Bates, E. (1978). Sentential devices for conveying givenness and newness: A cross-cultural development study. Journal of Verbal Learning and Verbal Behavior, 17, 539558.

MacWhinney, B. \& Bates, E. (Eds.). (1989). The crosslinguistic study of sentence processing. New York: Cambridge University Press.

MacWhinney, B. \& Osmán-Sági, J. (1991). Inflectional marking in Hungarian aphasics. To appear in a special issue on crosslinguistic aphasia in Brain and Language.

MacWhinney, B., Osmán-Sági, J., \& Slobin, D. (1991). Sentence comprehension in aphasia in two clear case-marking languages. To appear in a special issue on crosslinguistic aphasia in Brain and Language.

MacWhinney, B. \& Snow, C. (1985). The child language data exchange system. Journal of Child Language, 12, 271-296.

Menn, L. \& Obler, L.K. (Eds.). (1990). Agrammatic aphasia: Cross-language narrative sourcebook. Amsterdam: John Benjamins.

Miceli, G., Silveri, M.C., Romani, C., \& Caramazza, A. (1989). Variation in the pattern of omissions and substitutions of grammatical morphemes in the spontaneous speech of so-called agrammatic patients. Brain and Language, 36, 447-492.

Milberg, W. \& Blumstein, S. (1981). Lexical decision and aphasia: Evidence for semantic processing. Brain \& Language, 14, 371-385.

Norman, D. \& Bobrow, D. (1975). On data-limited and resource-limited processes. Cognitive Psychology, 7, 44-64.

Osmán-Sági, J. (1989). A note on action naming in Hungarian aphasic patients. (Tech. rep. No. 9012). San Diego: University of California, Center for Research in Language.

Ostrin, R. \& Schwartz, M. (1986). Reconstructing from a degraded trace: A study of sentence repetition in agrammatism. Brain \& Language, 28, 328-345.

Paradis, M. (1987). The assessment of bilingual aphasia. Hillsdale, NJ: Erlbaum.

Posner, M., Petersen, S., Fox, P., \& Raichle, M. (1988). Localization of cognitive operations in the human brain. Science, 240, 1627-1631.

Rizzi, L. (1980). A restructuring rule in Italian syntax. In S.J. Keyser (Ed.), Recent transformational studies in European languages. Cambridge, MA: MIT Press.

Rumelhart D. \& McClelland J.L.(Eds.). (1986). Parallel distributed processing: Explorations in the microstructure of cognition. Cambridge, MA: MIT Press.

Saffran, E., Berndt, R., \& Schwartz, M. (1989). The quantitative analysis of agrammatic production: Procedure and data. Brain \& Language, 37, 440 479.

Seidenberg, M., McClelland, J., \& Patterson, K. (1987, July). A distributed developmental model of visual word recognition, naming and dyslexia. Symposium on Connectionism. Abstracts of the Annual Meeting of the Experimental Psychological Society (U.K.). Oxford.

Shankweiler, D., Crain, S., Gorrell, P., \& Tuller, N. (1989). Reception of language in aphasia. Language and Cognitive Processes, 4, 1-33.

Slobin, D. (1991). Aphasia in Turkish: Speech production in Broca's and Wernicke's patients. To appear in a special issue on crosslinguistic aphasia in Brain and Language.

Smith, S. \& Bates, E. (1987). Accessibility of case and gender contrasts for agent-object assignment in Broca's aphasics and fluent anomics. Brain and Language, 30, 8-32.

Smith, S. \& Mimica, I. (1984). Agrammatism in a case-inflected language: Comprehension of agentobject relations. Brain and Language, 21, 274290.

Swinney, D., Zurif, E., \& Nicol, J. (1989). The effects of focal brain damage on sentence processing: An examination of the neurological organization of a mental module. Journal of Cognitive Neuroscience, 1, 25-37.

Tzeng, O., Bates, E., \& Wong, W. (1990). Chinese aphasia. Invited for submission to Scientific American.

Tzeng, O., Chen, S., \& Hung, D. (1991). Use of nominal classifiers by Chinese aphasic patients. To appear in a special issue on crosslinguistic aphasia in Brain and Language.

Vaid, J. \& Pandit, R. (1991). Sentence interpretation in normal and aphasic Hindi speakers. To appear in a special issue on crosslinguistic aphasia in Brain and Language.

Volterra, V. \& Bates, E. (1989). Selective impairment of Italian grammatical morphology in the congenitally deaf: A case study. Cognitive Neuropsychology, 6, 273-308.

Wulfeck, B. (1987). Sensitivity to grammaticality in agrammatic aphasia: Processing of word order and agreement violations. Doctoral dissertation, UCSD.

Wulfeck, B. (1988). Grammaticality judgments and sentence comprehension in agrammatic aphasia. 
Journal of Speech and Hearing Research, 31, 7281.

Wulfeck, B., Bates, E. (1990). Differential sensitivity to errors of agreement and word order in Broca's aphasia. Submitted for publication.

Wulfeck, B., Bates, E., \& Capasso, R. (1991). A crosslinguistic study of grammaticality judgments in Broca's aphasia. To appear in a special issue on crosslinguistic aphasia in Brain and Language.

Wulfeck, B., Bates, E., Juarez, L., Opie, M., Friederici, A., MacWhinney, B., \& Zurif, E. (1989). Pragmatics in aphasia: Crosslinguistic evidence. Language and Speech, 32, 315-336. 